\title{
PCR amplification of a putative gene for exo-1,3- $\beta$-glucanase to identify the pathogenic oomycete Pythium insidiosum
}

\begin{abstract}
Angsana Keeratijaruta, c, Tassanee Lohnoo ${ }^{\mathrm{b}}$, Wanta Yingyong ${ }^{\mathrm{b}}$, Umporn Nampoon ${ }^{\mathrm{a}}$, Tassanee Lerksuthirat $^{\mathrm{a}, \mathrm{c}}$, Pornpit Onpaew ${ }^{\mathrm{a}}$, Piriyaporn Chongtrakool ${ }^{\mathrm{a}}$, Theerapong Krajaejun ${ }^{\mathrm{a}}$ ${ }^{a}$ Department of Pathology, Faculty of Medicine, Ramathibodi Hospital, ${ }^{b}$ Research center, Faculty of Medicine, Ramathibodi Hospital, ' Department of Radiology, Faculty of Medicine, Ramathibodi Hospital, ${ }^{d}$ Multidiscipinary Unit, Faculty of Science, Mahidol University, Bangkok 10400, Thailand
\end{abstract}

\begin{abstract}
Background: Pythium insidiosum is the etiologic agent of pythiosis, a life-threatening infectious disease. Diagnosis of pythiosis is difficult and often delayed. Early diagnosis can lead to prompt treatment, and therefore a better prognosis for patients with pythiosis. Molecular diagnostic techniques are useful if microbiological and immunological assays are not available, or in cases of suspected pythiosis that test negative by other methods. So far, PCR identification of $P$. insidiosum has been largely relied on amplification of the rDNA region. Objective: To evaluate the diagnostic performance of Dx3 and Dx4 primers specific for a putative gene for exo1,3- $\beta$-glucanase (PinsEXO1), which encodes a specific immunogen of $P$. insidiosum, for rapid single-round PCR identification of $P$. insidiosum, in comparison with the previously-reported rDNA-specific primers, ITSpy1 and ITSpy2.

Materials and Methods: Genomic DNA (gDNA) from 35 P. insidiosum isolates and 48 control organisms were prepared to evaluate the diagnostic performance of the PinsEXO1- and rDNA-specific primers.

Results: When amplifying the control gDNA by using the Dx3/4 and ITSpy1/2 primer sets, no PCR product was observed, indicating that both primer sets had $100 \%$ detection specificity. When amplifying the $P$. insidiosum gDNA, the Dx3/4 primers provided an expected 550-bp amplicon for all 35 isolates, while the ITSpy1/2 primers provided an expected 230-bp amplicon for only 32 isolates. Thus, detection sensitivity of the Dx3/4 and ITSpy $1 / 2$ primer sets were $100 \%$ and $91 \%$, respectively.

Conclusion: By using the Dx3/4 primers, PinsEXO1 was an alternative, efficient, and novel PCR target for rapid single-round PCR identification of $P$. insidiosum.
\end{abstract}

Keywords: Diagnosis, oomycete, PCR, pythiosis, Pythium insidiosum

The aquatic, fungus-like, oomycetous organism Pythium insidiosum is the etiologic agent of pythiosis, a life-threatening infectious disease of humans and animals living in tropical and subtropical areas of the world [1]. The natural habitat of $P$. insidiosum is swampy areas, such as rice fields and ponds. $P$. insidiosum grows as a hyphae, and produces asexual zoospores, which can disseminate to infect humans and animals [2]. Patients usually present with clinical features associated with either cutaneous infection (ulcerating skin lesions), vascular infection

Correspondence to: Theerapong Krajaejun, MD, Department of Pathology, Faculty of Medicine, Ramathibodi Hospital Mahidol University, Bangkok 10400, Thailand.

E-mail:mr_en@hotmail.com (gangrenous ulceration of extremities from arterial insufficiency), ocular infection (corneal ulcer), or infection of internal organs [1, 3, 4]. Morbidity and mortality rates for pythiosis are high. Diagnosis of pythiosis is difficult and often delayed. Conventional antifungal drugs are generally ineffective against $P$. insidiosum. The treatment of choice for pythiosis is extensive surgical removal of infected organ. Many patients die from an advanced infection.

Early diagnosis and prompt treatment can minimize the morbidity and mortality rates of pythiosis. Definitive diagnosis of pythiosis can be made by culture identification [5], immunohistological assays [6-8], and serodiagnostic tests [9-20]. Some limitations have been observed in these assays. For example, the culture identification technique is a time consuming, requires 
experience, and is relatively insensitive. Serodiagnostic tests usually fail to detect anti-P. insidiosum antibody in patients with ocular pythiosis. A tissue sample (i.e. paraffin-embedded tissue) is often the only available source of specimen for diagnosis of pythiosis. In such case, diagnosis using an immunohistological assay is more suitable. However, the immunohistological assay requires a specific rabbit anti-P. insidiosum antibody, which is not routinely available. Moreover, cross reactivity with some other pathogenic fungi (i.e., Conidiobolus and Fusarium species) compromises the specificity of the assay [7, 21].

As an alternative assay, molecular diagnostic techniques, i.e. sequence homology analysis and PCR amplification, have been employed to detect $P$. insidiosum in infected tissues or pure cultures [22]. The molecular target for identifying P. insidiosum has been largely relied on the rDNA region (also known as the ribosomal RNA (rRNA) gene repeat) [22]. The rDNA region presents in the genome of most eukaryotes, and comprises 18S rRNA, internal transcribed spacer 1 (ITS1), 5.8S rRNA, ITS2, 28S rRNA, and the intergenic spacer. The rDNA region is a popular diagnostic target because it is a multicopy gene and it contains variable regions (ITS1, ITS2, and the intergenic spacer) for differentiation at the species level [22].

Sequence homology analysis is a multistep and time consuming procedure, comprising PCR amplification, DNA sequencing, and BLAST searching [18, 23-26]. Some investigators preferably use rapid single-round [18] or nested [21, 27, 28] PCR for direct detection of $P$. insidiosum. Vanittanakom et al. [18] demonstrate that their ITSpy1 and ITSpy2 primers successfully amplified all four $P$. insidiosum Thai isolates tested, while the PI-1 and PI-2 primers, used by Znajda et al. [27], Grooters et al. [21], and Botton et al. [28], failed to amplify one Thai isolate. Thus, the ITSpy $1 / 2$ primers appear to be more efficient than the PI-1/2 primers for identification of the Thai isolates. However, an evaluation with an extended number of both $P$. insidiosum isolates and fungal controls is needed to further determine diagnostic performance of the ITSpy $1 / 2$ primers.

Recently, we reported a putative gene for exo1,3- $\beta$-glucanase (PinsEXO1), which encodes a specific immunoreactive protein of $P$. insidiosum [29]. The PinsEXO1-coding sequences of all 22 $P$. insidiosum isolates tested are conserved, suggesting that the gene can be a potential PCR target for
$P$. insidiosum identification. In the present study, we aimed to design and evaluate PinsEXO1-specific primers Dx3 and Dx4 for rapid single-round PCR identification of $P$. insidiosum, in comparison with the rDNA-specific primers, ITSpy1 and ITSpy2.

\section{Materials and methods Microorganisms}

Thirty-five clinical $(n=31)$ and environmental $(n=4)$ isolates of $P$. insidiosum were used for genomic DNA (gDNA) preparation. Identity of all $P$. insidiosum isolates was confirmed by culture identification and zoospore induction [5]. Forty-eight culture-proven isolates of various fungi (Table 1) from the Clinical Microbiology Laboratory, Department of Pathology, Faculty of Medicine, Ramathibodi Hospital, Mahidol University, were also used for gDNA preparation (Table 1). All microorganisms were maintained on Sabouraud dextrose agar until use. This study was approved by the Committee on Human Rights Related to Research Involving Human Subjects at the Faculty of Medicine, Ramathibodi Hospital, Mahidol University. Informed consent from the patients providing the samples from which the isolates were originally obtained was waived because these patients are unknown to the current investigators and the data was analyzed anonymously, nor is it the intention of the authors to identify any patients retrospectively.

\section{Genomic DNA extraction}

Extraction of $P$. insidiosum gDNA was performed using a modification of the method reported by Aljanabi et al. [30]. Briefly, a hyphal mat ( 100 mg), harvested from 7-day culture in Sabouraud dextrose broth, was ruptured with glass beads (diameter, 710-1,180 $\mu \mathrm{m}$; Sigma, St. Louis, MO, USA) in the presence of $400 \mu \mathrm{L}$ of the salt homogenizing buffer $(0.4 \mathrm{M} \mathrm{NaCl}$, 10 mM Tris-HCl (pH 8.0), 2 mM EDTA), using TissueLyzer MM301 (Qiagen, Hilden, Germany). SDS (17\% (wt/vol); $45 \mu \mathrm{L})$ and proteinase $\mathrm{K}(20 \mathrm{mg} / \mathrm{mL}$; $8 \mu \mathrm{L}$ ) were added to the cell lysate and incubated at $56^{\circ} \mathrm{C}$ for overnight. $\mathrm{NaCl}(6 \mathrm{M}$; $0.3 \mathrm{~mL})$ was then added. The mixture was briefly vortexed and centrifuged $(10,000 \times g$ for $30 \mathrm{~min})$. Supernatant obtained was added to an equal volume of isopropanol, mixed, stored at $-20^{\circ} \mathrm{C}$ for $1 \mathrm{~h}$, and centrifuged $(10,000$ $\times g$ for $20 \mathrm{~min}$ ). The pellet was washed with $70 \%$ ethanol, air dried, and dissolved in 50-100 $\mu \mathrm{L}$ sterile water. 
Table 1. Pythium insidiosum isolates $(\mathrm{n}=35)$ and fungal controls $(\mathrm{n}=48)$ used for genomic DNA preparation in this study.

\begin{tabular}{|c|c|}
\hline Microorganism & Number of isolates \\
\hline Pythium insidiosum ${ }^{\mathrm{a}}$ & 35 \\
\hline Cryptococcus neoformans & 2 \\
\hline Penicillium marneffei & 1 \\
\hline Candida species $^{\mathrm{b}}$ & 12 \\
\hline Aspergillus species ${ }^{c}$ & 3 \\
\hline Mucor species & 3 \\
\hline Rhizopus species & 2 \\
\hline Absidia species & 1 \\
\hline Saksenaea species & 1 \\
\hline Conidiobolus species & 1 \\
\hline Basidiobolus species & 1 \\
\hline Microsporum gypseum & 1 \\
\hline Trichophyton species ${ }^{\mathrm{d}}$ & 4 \\
\hline Trichosporon species ${ }^{\mathrm{e}}$ & 2 \\
\hline Trichoderma species & 1 \\
\hline Fusarium species & 4 \\
\hline Curvularia species & 1 \\
\hline Geotrichum species & 1 \\
\hline Rhodotorula species & 1 \\
\hline Torulopsis glabrata & 2 \\
\hline Acremonium species & 2 \\
\hline Scedosporium apiospermum & 1 \\
\hline Exophiala jeanselmei & 1 \\
\hline
\end{tabular}

${ }^{a} P$. insidiosum isolated from patients with vascular pythiosis $(n=14)$, patients with ocular pythiosis $(n=10)$, patients with cutaneous pythiosis $(n=3)$, patients with other forms of pythiosis $(n=2)$, isolated from animals $(\mathrm{n}=2)$, and isolated from environment $(\mathrm{n}=4)$

${ }^{\mathrm{b}}$ Candida species were C. albicans $(\mathrm{n}=2)$, C. tropicalis $(\mathrm{n}=2)$, C. parapsilosis $(\mathrm{n}=2)$, C. guilliermondii $(\mathrm{n}=2), C$. rugosa $(\mathrm{n}=1), C$. lusitaniae $(\mathrm{n}=1), C$. laurentii $(\mathrm{n}=1)$, and $C$. dubliniensis $(\mathrm{n}=1)$

'Aspergillus species were A. flavus $(\mathrm{n}=1)$, A. terreus $(\mathrm{n}=1)$, and A. fumigatus $(\mathrm{n}=1)$

${ }^{\mathrm{d}}$ Trichophyton species were $T$. rubrum $(\mathrm{n}=3)$, T. mentagrophytes $(\mathrm{n}=1)$

'Trichosporon species were T. asahii $(\mathrm{n}=1)$, T. mucoides $(\mathrm{n}=1)$

Extraction of gDNA of the fungal controls (Table 1) was performed using a modification of the method reported by Muller et al. [31] and Niu et al. [32]. Briefly, portions of hyphal colony (about 50-100 mg) were harvested from actively growing (5-7-day-old) cultures on Sabouraud dextrose agar, and transferred to a $1.7 \mathrm{~mL}$ tube. Lysis buffer (600 $\mu \mathrm{L}$ of $100 \mathrm{mM}$ Tris- $\mathrm{HCl}$ (pH 8.0), 50 mM EDTA, $500 \mathrm{mM} \mathrm{NaCl}, 0.2 \%$ 2-mercaptoethanol (v/v), and $0.3 \%$ SDS) was added to each sample, vortexed vigorously with glass beads (diameter, $710-1,180 \mu \mathrm{m}$; Sigma), and incubated at $65^{\circ} \mathrm{C}$ for $3 \mathrm{~h}$. The cell lysate was centrifuged at $10,000 \times g$ for $10 \mathrm{~min}$. DNA was extracted with an equal volume of phenol:chloroform (1:1). To precipitate DNA, 0.1 volume of $3 \mathrm{M}$ potassium acetate buffer (pH 5.2) and 2 volumes of absolute ethanol were added to the mixture, incubated at $-20^{\circ} \mathrm{C}$ for $30 \mathrm{~min}$, and centrifuged at $10,000 \times \mathrm{g}$ for $10 \mathrm{~min}$. The DNA pellet was then washed with $70 \%$ ethanol, dried, and resuspended in $40 \mu \mathrm{L}$ of TE.

The concentration and purity of all DNA samples was estimated by measurement of optical density at 260 and $280 \mathrm{~nm}$ wavelengths using a NanoDrop 2000 spectrophotometer (Thermo Scientific). All DNA samples were stored at $-30^{\circ} \mathrm{C}$ until use.

\section{Polymerase chain reaction}

The PCR amplifications were performed in a 25 $\mu \mathrm{L}$ mixture comprising $100 \mathrm{ng}$ gDNA template, $10 \mathrm{mM}$ each primer, $1.5 \mathrm{mM} \mathrm{MgCl}_{2}, 0.2 \mathrm{mM}$ dNTP mixture 
(Promega, Madison, WI, USA), and 0.5 UI Taqpolymerase (Fermentas, Hanover, MD, USA) in $1 \times$ Taq-polymerase buffer. Amplification reactions were conducted in a Mastercycler-Pro thermal cycler (Eppendorf, Westbury, NY, USA) with the following settings: predenaturation at $94^{\circ} \mathrm{C}$ for $3 \mathrm{~min}, 25$ cycles of denaturation at $94^{\circ} \mathrm{C}$ for $45 \mathrm{~s}$, annealing at $55^{\circ} \mathrm{C}$ for $1 \mathrm{~min}$, and extension at $72^{\circ} \mathrm{C}$ for $1 \mathrm{~min}$, followed by the final extension at $72^{\circ} \mathrm{C}$ for $7 \mathrm{~min}$. Three pairs of primers were used to amplify all extracted gDNAs: (i) the fungal universal primer ITS1 (52 -TCCGTAGGTGAACCTGCGG-32) and ITS4 (52 -TCCTCCGCTTATTGATATGC-32 ) [21]; (ii) the rDNA-specific primer ITSpy1 (5'-CTGCGGAAGGATCATTACC3') and ITSpy2 (5'-GTCCTCGGAGTATAGATCAG3) [18]; and (iii) the PinsEXO1-specific primer Dx3 (5-GCGAGTTCTGGCTCGACTTTA-3') and Dx4 (5'-ACAAGCGCCAAAAAGTCCCA-3') designed by using the Primer-BLAST program [33], and the PinsEXO1 accession number GU994093.1 [29]. A negative control (no template) was included in each round of PCR assays. The GeneRuler 100-bp plus DNA ladder (Fermentas) was used to indicate molecular size. Size and amount of each PCR product were analyzed by $1 \%$ agarose gel electrophoresis, and image captured by Molecular Imager Gel Doc XR+ (Bio-Rad, Hercules, CA, USA).

\section{DNA sequencing}

The primer Dx3 used to sequence the PinsEXO1derived amplicon, and primer ITSpy1 was used to sequence the rDNA-derived amplicon. PCR products were purified using a NucleoSpinR Gel and PCR clean-up kit (NucleoSpin, Macherey-Nagel, Duren, Germany). Direct sequencing was performed using a Big Dye Terminator v. 3.1 Cycle Sequencing Kit (Applied Biosystems, Foster City, CA, USA). Automated sequencing was performed and analyzed using an ABI 3100 Genetic Analyzer and the Applied Biosystems Sequencing software. For sequence homology analysis, each sequences obtained was Blasted against the NCBI nucleotide database (http:/ /blast.ncbi.nlm.nih.gov/Blast.cgi).

\section{Results}

The negative control (no template) and the ITS1/ 4 fungal universal primers were included for a quality check of the gDNA samples from all 83 organisms (Table 1). After PCR amplification with the ITS1/4, ITSpy1/2, and newly-designed Dx3/4 (sequences and annealing locations are shown in Figure 1) primers, the negative control did not provide any product by gel electrophoresis. The ITS1/4 primers successfully amplified rDNA from all gDNA samples tested (Table 1). When amplifying gDNA samples from the fungal controls ( $n=48$; Table 1), the ITSpy $1 / 2$ primers (which target rDNA) and the Dx3/4 primers (which target PinsEXO1) provided no band. Thus, detection specificity of these primer sets were equally $100 \%$.

When testing the gDNA samples, extracted from all $P$. insidiosum isolates, the ITSpy $1 / 2$ primers produced an intense band from 29 samples, a very faint band from 3 samples (the isolate P11, NAN06, and SIMI7695.48), and no band from 3 samples (isolates P8, P13, and P21) (Figure 2B). The gDNA prepared from the $P$. insidiosum isolates $\mathrm{P} 1, \mathrm{P} 22$, and Pi-S provided a slightly smaller PCR product (approximately 220 bp), compared with the calculated amplicon size (approximately 230 bp) (Figure 2B). However, sequence homology analysis against the NCBI nucleotide database (BLASTN) showed that these amplicons matched the $P$. insidiosum rDNA. Overall, the ITSpy1/2 primers showed a detection sensitivity of $91.4 \%$.

The Dx3/4 primers successfully amplified a single, relatively-intense, 550-bp PCR product from gDNA templates of all $35 P$. insidiosum isolates tested (Figure 2A). Detection sensitivity of the Dx3/4 primers was therefore $100 \%$. BLASTN search against the NCBI nucleotide database matched these amplicons to PinsEXO1. The lowest amount of gDNA template required for a successful PCR amplification (limit of detection) of PinsEXO1, using the Dx3/4 primers, was $1 \mathrm{ng}$.

\section{Discussion}

Molecular diagnostic techniques for pythiosis are useful if microbiological and immunological assays are not available, or in suspected cases that test negative by other methods. So far, PCR identification of $P$. insidiosum has largely relied on amplification of the rDNA region [22]. As an alternative assay, we evaluated diagnostic performance of the PCR primers, Dx3 and Dx4, which target PinsEXO1 of P. insidiosum [29], in comparison with the previouslyreported rDNA-specific primers, ITSpy1 and ITSpy2 [18]. The primer Dx3 and Dx4 were designed by using the well-established program called Primer-BLAST [33], which is publicly available at the NCBI website (http://www.ncbi.nlm.nih.gov/tools/primer-blast). 


\begin{tabular}{|c|c|c|c|}
\hline Query & 1 & $\begin{array}{l}\text { ACTACGGYAACCTGAACCAGAGTCTCACGGCGGTCGAGGAGATCGTGAAGCGGTACGCGA } \\
\end{array}$ & 60 \\
\hline Sbjet & 1943 & ACTACGCCAACCTGAACCACTCCATTGTGGCCGTGGAGGCTATTATCAACCGCTACAAGG & 2002 \\
\hline Query & 61 & 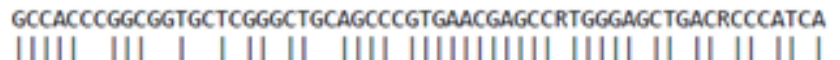 & 120 \\
\hline Sbjet & 2003 & GCCACAAGGCTATCATGGGTCTCGAGCCGGTGAACGAGCCATGGGAACTCACTCCTATTA & 2062 \\
\hline Query & 121 & 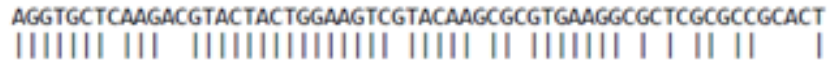 & 180 \\
\hline Sbjet & 2063 & AGGTGCTGAAGCGGTACTACTGGAAGTCCTACAAACGTGTGAAGGTGTTGGCTCCCTCGT & 2122 \\
\hline Query & 181 & GGAAGTTTGTGCTGCACGACTCGTTCCGCTITGGCCGCGAGTTCTGGCTCGACTTTÄTGC & 240 \\
\hline Sbjet & 2123 & GGAAATTCGTCATCCACGACTCGTTCCGCTTCGGTCTGCAGTTCTGGGCCAAGITCCTCA & 2182 \\
\hline Query & 241 & $\begin{array}{l}\text { GCGGSTGCCCGGACATTGCGATCGACACGCACATCTACCAGGCGTGGATGAACCCCGGCA } \\
\text { || }\end{array}$ & 300 \\
\hline Sbjet & 2183 & AGGGCTGCCCCGATATCGCTCTGGACACGCACATCTACCAGGCCTGGAACCCTCCTGGAA & 2242 \\
\hline Query & 301 & 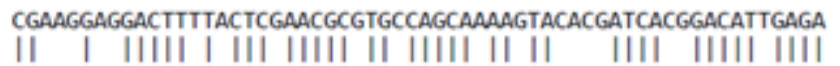 & 360 \\
\hline Sbjet & 2243 & CGGTTGCAGACTTCTTCTCCAACGCTTGTCAGCAGAAATATGTCATCAGTGACATGGAGA & 2302 \\
\hline Query & 361 & 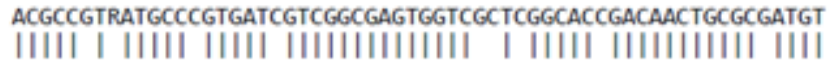 & 420 \\
\hline Sbjet & 2303 & ACGCCATGATGCCGGTGATTGTGGGGAGTGGTCTATTGGCACGGACAACTGCGCCATGT & 2362 \\
\hline Query & 421 & 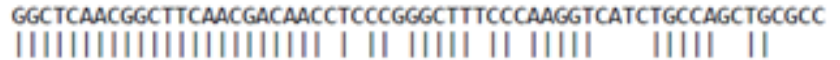 & 480 \\
\hline Sbjet & 2363 & GGCTCAACGGCTTCAACGACAACTTGCCTGGCTTCCCTAAGGTGCAGTGCCACATGATAG & 2422 \\
\hline Query & 481 & 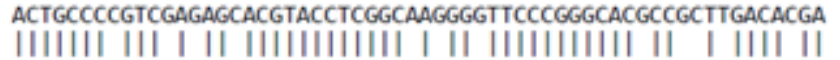 & 540 \\
\hline Sbjet & 2423 & ACTGCCCGGTCAACAGTACGTACCTCGGCGACGGCTTCCCGGGCACTCCTTTGGACAAGA & 2482 \\
\hline Query & 541 & 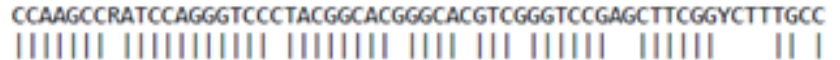 & 600 \\
\hline Sbjet & 2483 & CCAAGCCGATCCAGGGTCCATACGGCACTGGCATGTCTGGTCCGTCCTTCGGTAAGTGTC & 2542 \\
\hline Query & 601 & 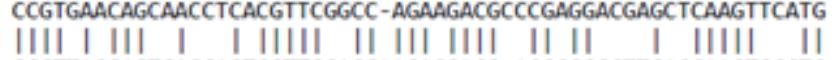 & 659 \\
\hline Sbjet & 2543 & CCGTTACCAGTCAGGACTCGTTCCACCAAGACGACG - ACGCGGCGTTGACCAAGTCGCTG & 2601 \\
\hline Query & 660 & 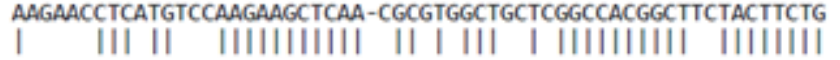 & 718 \\
\hline Sbjet & 2602 & A- - - CTC-TG--AAGAAGCTCAATGGCTTCGCTAAT-GGCCACGGCTGGTACTTCTG & 2651 \\
\hline Query & 719 & 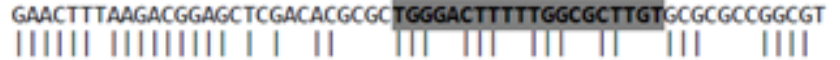 & 778 \\
\hline Sbjet & 2652 & GAACTTCAAGACGGAGTTTGCGACCAAGTGGAGCTTCCTGGACCTATGGCGTATGGGCGC & 2711 \\
\hline Query & 779 & $\begin{array}{l}\text { CATGCCCAAGAACATCTCGGACTATGACGACGCCGACGGCATCTTTGACGCGTGCGAGCG } \\
|||||||||||||||||||||||||||||||||||l| \mid\end{array}$ & 838 \\
\hline Sbjet & 2712 & CTTCCCCAAGAACGTGTCGGACTACCACGAGAGCGATGGAGTGGAGAGAGCGTGTGTGAA & 2771 \\
\hline Query & 839 & 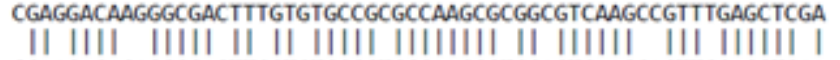 & 898 \\
\hline Sbjet & 2772 & GGAAGACAGAGGCGAGTTCGTCTGCCGTGCCAAGCGTGGAGTCAAGGAGTTCGAGCTCAA & 2831 \\
\hline & 89 & $\begin{array}{l}\text { GAACGGACTCGCGTACGCGTGCAAC } 923 \\
\||||||||||||||||| \mid\end{array}$ & \\
\hline Sbjet & & IGCGGCCTCGCGTTCGCGTGCAAC 2856 & \\
\hline
\end{tabular}

Figures 1. Sequences and annealing locations of the primer Dx3 (first gray box) and Dx4 (second gray box; reverse complement sequence) in reference to the putative exo-1,3- $\beta$-glucanase genes from Pythium insidiosum (Query sequence; accession number, GU994093.1) and Phytophthora infestans (Subject sequence; accession number, AF494014.1). The primer Dx3 and Dx4 perfectly anneal to the P. insidiosum glucanase gene, but failed to properly anneal to the $P$. infestans glucanase gene. Sequence alignment analysis of the glucanase genes from $P$. insidiosum and $P$. infestans (performing online at http://blast.ncbi.nlm.nih.gov/Blast.cgi) shows an E-value of $4^{\mathrm{e}-141}$, with identities of $72 \%$, and a gap of $1 \%$. 


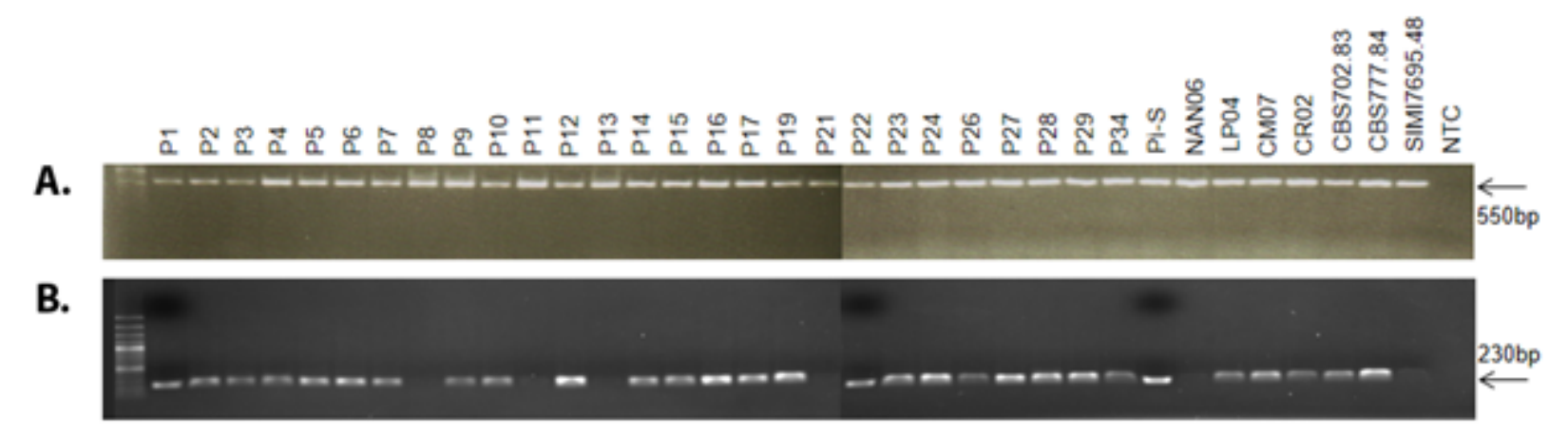

Figure 2. Gel electrophoresis showing the PCR products amplified from gDNA of the 35 P. insidiosum isolates by using: (A) the Dx3/4 primers, which target the putative exo-1,3- $\beta$-glucanase gene of $P$. insidiosum or PinsEXO1 (amplicon size, 550bp); and (B) the ITSpy1/2 primers, which target the rDNA region of $P$. insidiosum (amplicon size, 230bp) (NTC, no-template control).

Based on a given DNA target sequence (e.g. PinsEXO1), the Primer-BLAST program selects the most suitable primer set and uses the BLAST and global alignment algorithm to evaluate the selected primers for any cross annealing against all genes deposited in the NCBI nucleotide database. Thus, the resulting primers (Dx3 and Dx4) should be specific to the target sequence.

The PCR template was adequately present in all reactions, because the ITS1/4 universal primers can amplify an expected amplicon from all 83 gDNA samples included in this study. The no-template controls (included in each round of PCR assays) were all negative, indicating that there was no DNA contamination that could lead to a false positive result. To evaluate the specificity of detection, we collected 48 different culture-proven fungal microorganisms (Table 1), as controls in the PCR assay evaluation. We also included a number of Aspergillus spp. and Zygomycetes, because these fungi have microscopic features that could be confused with $P$. insidiosum. When the Dx3/4 and ITSpy1/2 primers were used to amplify gDNA prepared from the fungal controls (Table 1), no PCR product was observed by gel electrophoresis. This result indicates that there was no nonspecific primer annealing to gDNA of the fungal controls, and thus, both primer sets equivalently had $100 \%$ specificity.

To evaluate sensitivity of detection, gDNA prepared from all 35 culture-proven $P$. insidiosum isolates was amplified by PCR using the Dx3/4 and ITSpy $1 / 2$ primers. The ITSpy1/2 primers can amplify an expected amplicon from 32 out of 35 isolates tested, although three isolates (P11, NAN06, and SIMI7695.48), could be interpreted as negative because of a very faint PCR band (Figure 2B). In addition, gDNA of a few P. insidiosum isolates (P1, $\mathrm{P} 22$, and Pi-S) gave an unexpectedly smaller amplicon (approximately $220 \mathrm{bp}$ rather than approximately 230 bp), suggesting some variations in the rDNA region of $P$. insidiosum (Figure 2B). Overall, we considered the detection sensitivity of the ITSpy $1 / 2$ primers was compromised, and thus, calculated to be $91 \%$. By contrast, based on the same set of gDNA samples, the Dx3/4 primers successfully amplified the expected intense PCR product (approximately $550 \mathrm{bp)}$ from all $P$. insidiosum gDNA samples tested (Figure 2A). Therefore, the Dx3/4 primers had a better detection sensitivity (100\%), when compared with that of the ITSpy1/2 primers (91\%).

In conclusion, we demonstrated here that, when amplifying the gDNA templates of 35 P. insidiosum isolates and 48 fungal controls (Table 1), that the ITSpy $1 / 2$ primers had excellent detection specificity (100\%), but limited detection sensitivity (91\%). By using the same set of templates for PCR amplification with the Dx3/4 primers, we found that PinsEXO1 was a more efficient PCR target (100\% detection specificity and sensitivity) and can be used an alternative marker for molecular identification of P. insidiosum.

\section{Acknowledgments}

This study was supported by the Thailand Research Fund-The Commission on Higher Education-Mahidol University Grant (T. Krajaejun), the Mahidol University Research Grant (T. Krajaejun), the Ramathibodi Hospital Research Grant (T. Krajaejun, T. Lohnoo), and the Royal Golden Jubilee Ph.D. Scholarships from the Thailand 
Research Fund (A. Keeratijarut, T. Lerksuthirat,). We are grateful to Angkana Chaiprasert for providing the clinical isolates. No author has any conflict of interest.

\section{References}

1. Mendoza L, Ajello L, McGinnis MR. Infection caused by the oomycetous pathogen Pythium insidiosum. J Mycol Med. 1996; 6:151-64.

2. Mendoza L, Hernandez F, Ajello L. Life cycle of the human and animal oomycete pathogen Pythium insidiosum. J Clin Microbiol. 1993; 31:2967-73.

3. Sathapatayavongs B, Leelachaikul P, Prachaktam R, Atichartakarn V, Sriphojanart S, Trairatvorakul P, et al. Human pythiosis associated with thalassemia hemoglobinopathy syndrome. J Infect Dis. 1989; 159: 274-80.

4. Krajaejun T, Sathapatayavongs B, Pracharktam R, Nitiyanant P, Leelachaikul P, Wanachiwanawin W, et al. Clinical and epidemiological analyses of human pythiosis in Thailand. Clin Infect Dis. 2006; 43:569-76.

5. Chaiprasert A, Samerpitak K, Wanachiwanawin W, Thasnakorn P. Induction of zoospore formation in Thai isolates of Pythium insidiosum. Mycoses. 1990; 33:317-23.

6. Brown CC, McClure JJ, Triche P, Crowder C. Use of immunohistochemical methods for diagnosis of equine pythiosis. Am J Vet Res. 1988; 49:1866-8.

7. Keeratijarut A, Karnsombut P, Aroonroch R, Srimuang S, Sangruchi T, Sansopha L, et al. Evaluation of an in-house immunoperoxidase staining assay for histodiagnosis of human pythiosis. Southeast Asian J Trop Med Public Health. 2009; 40:1298-305.

8. Triscott JA, Weedon D, Cabana E. Human subcutaneous pythiosis. J Cutan Pathol. 1993; 20: 267-71.

9. Mendoza L, Kaufman L, Standard PG. Immunodiffusion test for diagnosing and monitoring pythiosis in horses. J Clin Microbiol. 1986; 23:813-6.

10. Mendoza L, Nicholson V, Prescott JF. Immunoblot analysis of the humoral immune response to Pythium insidiosum in horses with pythiosis. J Clin Microbiol. 1992; 30:2980-3.

11. Mendoza L, Kaufman L, Mandy W, Glass R. Serodiagnosis of human and animal pythiosis using an enzyme-linked immunosorbent assay. Clin Diagn Lab Immunol. 1997; 4:715-8.

12. Imwidthaya P, Srimuang S. Immunodiffusion test for diagnosing human pythiosis. Mycopathologia. 1989; 106:109-12.

13. Pracharktam R, Changtrakool P, Sathapatayavongs B,
Jayanetra P, Ajello L. Immunodiffusion test for diagnosis and monitoring of human pythiosis insidiosi. J Clin Microbiol. 1991; 29:2661-2.

14. Krajaejun T, Kunakorn M, Niemhom S, Chongtrakool P, Pracharktam R. Development and evaluation of an in-house enzyme-linked immunosorbent assay for early diagnosis and monitoring of human pythiosis. Clin Diagn Lab Immunol. 2002; 9:378-82.

15. Krajaejun T, Kunakorn M, Pracharktam R, Chongtrakool P, Sathapatayavongs B, Chaiprasert A, et al. Identification of a novel 74-kiloDalton immunodominant antigen of Pythium insidiosum recognized by sera from human patients with pythiosis. J Clin Microbiol. 2006; 44:1674-80.

16. Krajaejun T, Imkhieo S, Intaramat A, Ratanabanangkoon K. Development of an immunochromatographic test for rapid serodiagnosis of human pythiosis. Clin Vaccine Immunol. 2009; 16:506-9.

17. Grooters AM, Leise BS, Lopez MK, Gee MK, O’Reilly KL. Development and evaluation of an enzyme-linked immunosorbent assay for the serodiagnosis of pythiosis in dogs. J Vet Intern Med. 2002; 16:142-6.

18. Vanittanakom N, Supabandhu J, Khamwan C, Praparattanapan J, Thirach S, Prasertwitayakij N, et al. Identification of emerging human-pathogenic Pythium insidiosum by serological and molecular assay-based methods. J Clin Microbiol. 2004; 42:3970-4.

19. Jindayok T, Piromsontikorn S, Srimuang S, Khupulsup $\mathrm{K}$, Krajaejun T. Hemagglutination test for rapid serodiagnosis of human pythiosis. Clin Vaccine Immunol. 2009; 16:1047-51.

20. Supabandhu J, Vanittanakom P, Laohapensang K, Vanittanakom N. Application of immunoblot assay for rapid diagnosis of human pythiosis. J Med Assoc Thai. 2009; 92:1063-71.

21. Grooters AM, Gee MK. Development of a nested polymerase chain reaction assay for the detection and identification of Pythium insidiosum. J Vet Intern Med. 2002; 16:147-52.

22. Krajaejun T, Satapatayavong B, Sullivan TD. Pythium. In: Liu D, Editor. Molecular Detection of Human Fungal Pathogens. New York: CRC Press; 2011. p. 837-49.

23. Badenoch PR, Coster DJ, Wetherall BL, Brettig HT, Rozenbilds MA, Drenth A, et al. Pythium insidiosum keratitis confirmed by DNA sequence analysis. Br J Ophthalmol. 2001; 85:502-3.

24. Reis JL, de Carvalho ECQ, Nogueira RHG, Lemos LS, Mendoza L. Disseminated pythiosis in three horses. Vet Microbiol. 2003; 96:289-95. 
25. Rivierre C, Laprie C, Guiard-Marigny O, Bergeaud P, Berthelemy M, Guillot J. Pythiosis in Africa. Emerg Infect Dis. 2005; 11:479-81.

26. Salipante SJ, Hoogestraat DR, SenGupta DJ, Murphey D, Panayides K, Hamilton E, et al. Molecular diagnosis of subcutaneous Pythium insidiosum infection by use of PCR screening and DNA sequencing. J Clin Microbiol. 2012; 50:1480-3.

27. Znajda NR, Grooters AM, Marsella R. PCR-based detection of Pythium and Lagenidium DNA in frozen and ethanol-fixed animal tissues. Vet Dermatol. 2002; 13:187-94.

28. Botton SA, Pereira DIB, Costa MM, Azevedo MI, Argenta JS, Jesus FPK, et al. Identification of Pythium insidiosum by nested PCR in cutaneous lesions of Brazilian horses and rabbits. Curr Microbiol. 2011; 62:1225-9.

29. Krajaejun T, Keeratijarut A, Sriwanichrak K, Lowhnoo T, Rujirawat T, Petchthong T, et al. The 74-kilodalton immunodominant antigen of the pathogenic oomycete
Pythium insidiosum is a putative exo-1,3- $\beta$-glucanase. Clin Vaccine Immunol. 2010; 17:1203-10.

30. Aljanabi SM, Martinez I. Universal and rapid saltextraction of high quality genomic DNA for PCRbased techniques. Nucleic Acids Res. 1997; 25: 4692-3.

31. Muller FM, Werner KE, Kasai M, Francesconi A, Chanock SJ, Walsh TJ. Rapid extraction of genomic DNA from medically important yeasts and filamentous fungi by high-speed cell disruption. J Clin Microbiol. 1998; 36:1625-9.

32. Niu C, Kebede H, Auld D, Woodward J, Burow G, Wright R. A safe inexpensive method to isolate high quality plant and fungal DNA in an open laboratory environment. Afr J Biotechnol. 2008; 7:2818-22.

33. Ye J, Coulouris G, Zaretskaya I, Cutcutache I, Rozen S, Madden TL. Primer-BLAST: a tool to design targetspecific primers for polymerase chain reaction. BMC Bioinformatics. 2012; 13:134. 